Original

\title{
Relationship between dental anxiety and pain perception during scaling
}

\author{
Sheetal Sanikop, Pallavi Agrawal and Suvarna Patil \\ Department of Periodontics, KLE V. K. Institute of Dental Sciences, KLE University, \\ Belgaum, Karnataka, India
}

(Received 9 February and accepted 2 July 2011)

\begin{abstract}
Dental pain, anxiety and fear are important factors that prevent patients from seeking dental care. In this study, we aimed to evaluate the pain perception of patients during scaling and its relationship with dental anxiety. One hundred dental patients participated in the study. Pain levels after scaling were assessed with a Visual Analog Scale (VAS) and an Anxiety Questionnaire consisting of seven questions. The mean VAS score for the entire study group was $17.3 \pm 13.8$ with no statistically significant differences between gender and different age groups. The mean anxiety score was $11.66 \pm 4.17$. This was significantly higher in women $(P=0.005)$, but there were no statistically significant differences between different age groups. There was a statistically significant correlation between VAS and total anxiety score $(P<0.001)$ as well as each question, except for questions number 3 and 4 in men. Patients were found to experience only limited pain during scaling. They were anxious because they expected pain, women being more anxious than men. Hence, dentists should seek to alleviate or reduce pain and anxiety related to treatment not only to successfully complete the treatment, but also to sustain and carry the patients into successful maintenance and patient recall. (J Oral Sci 53, 341-348, 2011)
\end{abstract}

Keywords: pain; dental anxiety; scaling.

Correspondence to Dr. Pallavi Agrawal, Department of Periodontics, KLE V. K. Institute of Dental Sciences, KLE University, Belgaum, Karnataka 590010, India Tel: +91-9379621830

E-mail: pallavi_07@hotmail.com \& pallavi9711@gmail.com

\section{Introduction}

Pain is described by the Subcommittee on Taxonomy of the International Association for the Study of Pain (IASP) as "an unpleasant sensory and emotional experience associated with actual or potential tissue damage, or described in terms of such damage" (1).

Stedman's Medical Dictionary gives a more complete definition of pain as "an unpleasant sensation associated with actual or potential tissue damage and mediated by specific nerve fibres to the brain, where its conscious appreciation may be modified by various factors" (2). This definition recognizes that pain may have a noxious transmission component, a psychological component and a very important modulatory component.

Pain is not simply determined by the intensity of nociceptive stimulation (3). Pain is as much a cognitive and emotional construct as it is a physiological experience (4). Rhudy and Meagher evaluated the effect of fear and anxiety on pain reactivity in humans. The results of that study supported the fact that emotional states modulate human pain reactivity (5).

Dental anxiety and dental fear are strong negative feelings associated with dental treatments and are often used interchangeably in the dental literature. Dental anxiety was described by Klingberg and Broberg as a state of apprehension that something dreadful is going to happen in relation to dental treatment or certain aspects of dental treatment (3).

Fear of dental treatment is common. It may interfere with patients' compliance and result in deteriorating dental and periodontal health (6). Pain was also more likely to be reported by those with previous painful experiences and those who were anxious about dental 


\begin{tabular}{ll}
\hline Inclusion Criteria & Exclusion Criteria \\
\hline - Patients between the age range of 30-50 years & - Patients who refused to give informed consent \\
- Patients present with supragingival calculus on & - A medical or psychological disorder that might \\
the mandibular anterior teeth & affect pain thresholds \\
- No dentin sensitivity to air stimulation & - Use of pain or anxiety medication \\
- Patients with gingivitis with deepened & - Smoking habit and/or alcoholism \\
periodontal sulcus $<4 \mathrm{~mm}$ & - Presence of acute periodontal pain, pulpitis, \\
- Patients with mandibular anterior teeth free of & abscesses or other acute infections \\
$\begin{array}{l}\text { any restorations (root canal treatment, } \\
\text { composite, amalgam, aesthetic or prosthetic }\end{array}$ & - Patients with attachment loss and/or gingival \\
restorations) or orthodontic treatment & recession, and/or root hypersensitivity that \\
\hline
\end{tabular}

Fig. 1 Inclusion and exclusion criteria.

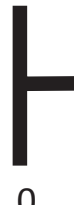

0

No pain

Fig. 2 Visual analog scale.

treatment and expected treatment to be painful (4). Periodontal therapy is also often associated with high levels of anxiety. In periodontal therapy, a relationship seems to exist between dental anxiety and pain experienced during scaling procedures and pain response after periodontal surgery (7).

Patients' perception of pain and dental anxiety differ with different periodontal procedures (8). Mechanical non-surgical therapy, or Scaling and Root planing (SRP), is the most commonly used procedure for treating gingivitis and periodontitis. These procedures may be perceived as painful (9). The experience of pain during preventive treatments such as probing and scaling may also discourage patients who do not have periodontitis. Supragingival debridement is the initial and essential phase before subgingival scaling and/or advanced periodontal procedures, and it is the first step of routine dental care and maintenance visits (7). Supragingival calculus removal procedures are also reported to cause pain in patients (10).

Dental anxiety also appears to be a gender-specific phenomenon being significantly correlated with the female gender (11). Patients' perception of pain and dental anxiety is also found to differ with individual characteristics such as age, smoking and oral health status (3).
Thus, this study aimed to evaluate patients' pain perception during scaling and its relationship with dental anxiety. It also evaluates differences in the pain perception between genders and its relationship with age.

\section{Materials and Methods}

\section{Study population}

One hundred patients (48 males and 52 females) reporting to the Department of Periodontology, KLE V. K. Institute of Dental Sciences, KLE University, Belgaum, Karnataka, India, were included in the study. These patients had passed at least the tenth grade level of education and were all of the same socio-economic group. To be included in the study, patients had to be between 30 to 50 years of age, present with supragingival calculus on the mandibular anterior teeth, have no dentin sensitivity to air stimulation, have gingivitis with deepened periodontal sulcus $<4 \mathrm{~mm}$ and have their mandibular anterior teeth free of any restorations (root canal treatment, composite, amalgam, aesthetic or prosthetic restorations) or orthodontic treatment (Fig. 1).

Exclusion criteria included refusal to give informed consent, a medical or psychological disorder that might affect pain thresholds, use of pain or anxiety medication, smoking habit and/or alcoholism, presence of acute periodontal pain, pulpitis, abscesses or other acute infections, attachment loss and/or gingival recession, and/or root hypersensitivity that might cause tooth sensitivity (Fig. 1).

\section{Procedure}

All procedures were performed by an experienced periodontist with patients sitting in the same dental chair. The calculus index (3) was recorded on the anterior six mandibular teeth as follows: none, discontinuous flecks, non-continuous band on parts of tooth, and continuous band around tooth. 


\begin{tabular}{|c|}
\hline Dental Anxiety Questionnaire Sheet \\
\hline $\begin{array}{l}\text { How much anxiety/fear or discomfort does each of these cause you? Please use the numbers from the scale for } \\
\text { the first three questions. 1. none at all } 2 \text {. a little } 3 \text {. somewhat } 4 \text {. much } 5 \text {. very much }\end{array}$ \\
\hline 1. Being seated in dental chair \\
\hline 2. Having your teeth cleaned \\
\hline 3. All things considered, how fearful are you of having dental work done? \\
\hline $\begin{array}{l}\text { 4. If you had to go to the dentist tomorrow, how would you feel about it? } \\
\text { a. I would look forward to it as a reasonably enjoyable experience. } \\
\text { b. I wouldn't care one way or another. } \\
\text { c. I would be a little uneasy about it. } \\
\text { d. I would be afraid that it would be unpleasant and painful. } \\
\text { e. I would be very frightened of what the dentist might do. }\end{array}$ \\
\hline $\begin{array}{l}\text { 5. When you are waiting in the dentist's office for your turn in the chair, how do you feel? } \\
\text { a. Relaxed } \\
\text { b. A little uneasy } \\
\text { c. Tense } \\
\text { d. Anxious } \\
\text { e. So anxious that I sometimes break out in a sweat or almost feel physically sick }\end{array}$ \\
\hline $\begin{array}{l}\text { 6. When you are in the dentist's chair waiting while she gets the drill ready to begin working on your teeth, how } \\
\text { do you feel? } \\
\text { a. Relaxed } \\
\text { b. A little uneasy } \\
\text { c. Tense } \\
\text { d. Anxious } \\
\text { e. So anxious that I sometimes break out in a sweat or almost feel physically sick }\end{array}$ \\
\hline $\begin{array}{l}\text { 7. You are in the dentist's chair to have your teeth cleaned. While you are waiting and the dental assistant is } \\
\text { getting out the instruments that the periodontist will use to clean your teeth around the gums, how do you feel? } \\
\text { a. Relaxed } \\
\text { b. A little uneasy } \\
\text { c. Tense } \\
\text { d. Anxious } \\
\text { e. So anxious that I sometimes break out in a sweat or almost feel physically sick }\end{array}$ \\
\hline Questions 1 through 3 originate from the DFS, and Questions 4 through 7 are from Corah's DAS. \\
\hline
\end{tabular}

Fig. 3 Dental anxiety questionnaire.

All patients underwent supragingival scaling of the anterior six mandibular teeth using the same piezoelectric ultrasonic handpiece and tips without local anaesthesia. Following supragingival scaling, written informed consent was obtained from the patients for their participation in the study. The patients were asked to indicate their level of pain on a 100-mm horizontal Visual Analog Scale (VAS) where zero meant 'no pain and discomfort' and 100 meant 'the worst possible pain and discomfort' (Fig. 2). VAS is considered to be a robust, sensitive and reproducible method of expressing pain severity (12). It is a simple, reliable, and valid pain measurement scale that has been used for evaluating dental pain (13), such as in previous studies that evaluated pain from periodontal therapies (14-16).

Dental anxiety was measured by using two anxiety measurement scales. One of the questionnaires was the Corah's Dental Anxiety Scale (DAS), which consists of four questions to assess dental anxiety (17). It is probably the most well-known adult questionnaire designed to assess dental anxiety (18). The other was the Dental Fear Survey (DFS), which consists of 20 questions (19). Karadottir et al. evaluated the DAS and DFS and found that only three of the 20 DFS questions and all four DAS questions significantly correlated with patients' responses to instrumentation (20). 
Table 1 Age and calculus index of subjects by gender

\begin{tabular}{lcccc}
\hline & Women $(n)$ & Men $(n)$ & $P$ & Total \\
\hline Age (in years; Mean \pm SD) & $39.81 \pm 7.26$ & $36.92 \pm 5.54$ & $0.122(\mathrm{NS})$ & $38.42 \pm 6.59$ \\
Calculus Index & & & & \\
$\quad$ Discontinuous flecks & 12 & 18 & $0.470(\mathrm{NS})$ & 22 \\
Non-continuous bands & 14 & 08 & \\
Continuous bands & 26 & 22 &
\end{tabular}

Table 2 Evaluation of Dental Anxiety Scores (DAS) and Visual analog scale (VAS) scores for each gender and the entire group

\begin{tabular}{lcc}
\hline & DAS & VAS \\
\hline Overall & $11.66 \pm 4.17$ & $17.3 \pm 13.8$ \\
Women & $13.19 \pm 4.74$ & $18.8 \pm 13.6$ \\
Men & $10.0 \pm 2.67$ & $15.7 \pm 14.0$ \\
$P$ & $0.005(\mathrm{~S})$ & $0.432(\mathrm{NS})$ \\
\hline
\end{tabular}

$\mathrm{S}=$ Significant; $\mathrm{NS}=$ Not significant

Therefore, in our study, the patients were asked to complete a questionnaire consisting of only these seven questions, as was done previously by Chung et al. and Guzeldemir et al. (3,21). The anxiety questionnaire scores ranged from 7 to 35 (Fig. 3). After completing the questionnaire, complete scaling was done for each patient followed by proper periodontal care and treatment.

\section{Statistical analysis}

For the quantitative variables, Kolmogorov-Smirnov test was conducted for testing normality. Normality was found for age, anxiety scores and VAS. The data was grouped by age (in years): $30-34,35-39,40-44$ and $\geq 45$. Mean and standard deviations were calculated for all the quantitative variables with respect to the entire group, for males, for females and for the different age groups. Student's unpaired $t$ test was conducted to compare gender differences between Anxiety Scores and VAS. One-way ANOVA was used to compare age differences between Anxiety Scores and VAS. Spearman's rank correlation coefficients were calculated to analyze the relationship between VAS and each question of the dental anxiety questionnaire (Q1, Q2, Q3, Q4, Q5, Q6, Q7) as well as the total Dental Anxiety Scores. The Chi-square test was used to compare the calculus index between the genders. Kruskal-Wallis test was conducted to test the homogeneity for calculus index (CI), Q1, Q2, Q3, Q4, Q5, Q6 and Q7. No significant difference was found for any of these variables with respect to the age groups. $P$ values $<0.05$ were considered statistically significant.

\section{Results}

One hundred dental patients (52 women and 48 men; mean age, $38.42 \pm 6.59$ years; age range, $30-50$ years) participated in the study. No statistically significant differences were found between men and women with regard to mean age $(P=0.122)$ and calculus index $(P=$ 0.470) (Table 1).

The mean VAS score for the entire group was $17.3 \pm$ 13.8 (range: 0-65) and the median interquartile range (IQR) was 15. The mean VAS scores for women and men were $18.8 \pm 13.6$ and $15.7 \pm 14.0$, respectively, and the median values were 18 and 12 , respectively. The difference in mean VAS scores between women and men was not statistically significant $(P=0.432)$. (Table 2$)$ VAS scores were evaluated for the following age groups: 30-34 years, 35-39 years, 40-44 years and $\geq 45$ years. There were no statistically significant differences in VAS scores among these age groups (Table 3).

The mean anxiety score for the entire study population was $11.66 \pm 4.17$ (range: $7-24$ ). The median was 11 . The questionnaire score was significantly higher in women $(13.19 \pm 4.74)$ than in men $(10 \pm 2.67)(P=0.005)$ (Table 2). The median was 13.5 for women and 10 for men. Anxiety scores according to different age groups showed no statistically significant differences (Table 3 ).

The relationship between patients' pain responses to scaling indicated by the VAS and dental anxiety scores were evaluated by the Spearman's rank correlation coefficient for total anxiety scores. There was a statistically significant correlation between VAS and total anxiety score $(P<0.001)$. When VAS was evaluated for each question, there was significant correlation except for questions number 3 and 4 in men (Tables 4-6).

\section{Discussion}

The present study provided information about pain perception of patients and the level of dental anxiety 
Table 3 Evaluation of Dental Anxiety Scores (DAS) and Visual Analog Scale (VAS) according to different age groups

\begin{tabular}{|c|c|c|c|c|c|c|}
\hline Age Groups (in years) & $30-34$ & $35-39$ & $40-44$ & $\geq 45$ & $P$ & Total \\
\hline $\begin{array}{c}\text { DAS } \\
(\mathrm{mm}, \text { mean } \pm \mathrm{SD})\end{array}$ & $12.20 \pm 4.77$ & $11.0 \pm 3.51$ & $9.82 \pm 2.89$ & $12.83 \pm 4.26$ & 0.314 (NS) & $11.66 \pm 4.17$ \\
\hline $\begin{array}{c}\text { VAS } \\
(\mathrm{mm}, \text { mean } \pm \mathrm{SD})\end{array}$ & $21.0 \pm 17.9$ & $15.7 \pm 9.8$ & $11.9 \pm 9.2$ & $16.9 \pm 10.7$ & $0.366(\mathrm{NS})$ & $17.3 \pm 13.8$ \\
\hline
\end{tabular}

$\mathrm{S}=$ Significant; NS = Not significant

Table 4 Correlation between DAS and VAS for the entire group

\begin{tabular}{lcccccccc}
\hline & Q1 & Q2 & Q3 & Q4 & Q5 & Q6 & Q7 & DAS \\
\hline Correlation coefficient & 0.614 & 0.614 & 0.484 & 0.361 & 0.486 & 0.6 & 0.64 & 0.642 \\
Significance level & $<0.001$ & $<0.001$ & 0.001 & 0.012 & 0.001 & $<0.001$ & $<0.001$ & $<0.001$ \\
$(P$ value $)$ & $(\mathrm{S})$ & $(\mathrm{S})$ & $(\mathrm{S})$ & $(\mathrm{S})$ & $(\mathrm{S})$ & $(\mathrm{S})$ & $(\mathrm{S})$ & $(\mathrm{S})$ \\
\hline
\end{tabular}

$\mathrm{S}=$ Significant; $\mathrm{NS}=$ Not significant

Table 5 Correlation between DAS and VAS for females

\begin{tabular}{lcccccccc}
\hline & Q1 & Q2 & Q3 & Q4 & Q5 & Q6 & Q7 & DAS \\
\hline Correlation coefficient & 0.745 & 0.683 & 0.631 & 0.562 & 0.484 & 0.67 & 0.662 & 0.728 \\
Significance level & $<0.001$ & 0.001 & 0.002 & 0.005 & 0.016 & 0.001 & 0.001 & $<0.001$ \\
$(P$ value $)$ & $(\mathrm{S})$ & $(\mathrm{S})$ & $(\mathrm{S})$ & $(\mathrm{S})$ & $(\mathrm{S})$ & $(\mathrm{S})$ & $(\mathrm{S})$ & $(\mathrm{S})$ \\
\hline
\end{tabular}

$\mathrm{S}=$ Significant; $\mathrm{NS}=$ Not significant

Table 6 Correlation between DAS and VAS for the entire group

\begin{tabular}{lcccccccc}
\hline & Q1 & Q2 & Q3 & Q4 & Q5 & Q6 & Q7 & DAS \\
\hline Correlation coefficient & 0.456 & 0.571 & 0.304 & -0.055 & 0.462 & 0.516 & 0.608 & 0.586 \\
Significance level & 0.029 & 0.006 & 0.145 & 0.793 & 0.027 & 0.013 & 0.004 & 0.005 \\
$(P$ value $)$ & $(\mathrm{S})$ & $(\mathrm{S})$ & $(\mathrm{NS})$ & $(\mathrm{NS})$ & $(\mathrm{S})$ & $(\mathrm{S})$ & $(\mathrm{S})$ & $(\mathrm{S})$ \\
\hline
\end{tabular}

$\mathrm{S}=$ Significant; NS = Not significant

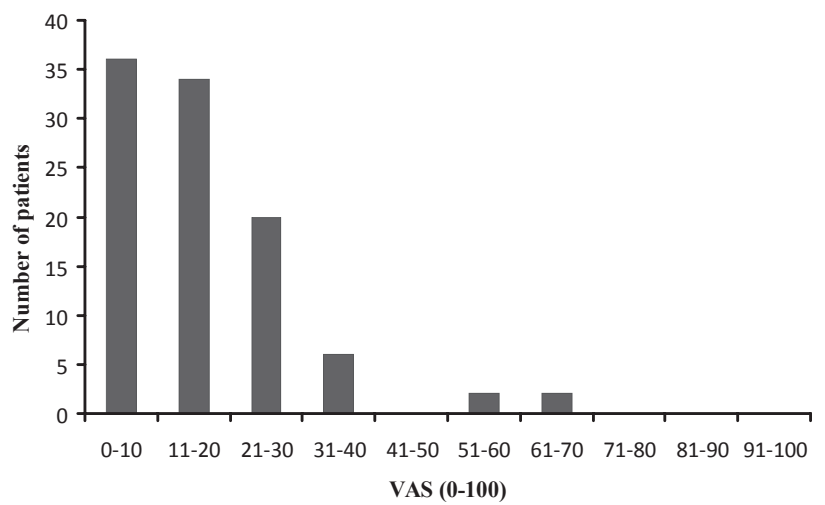

Fig. 4 Patients' pain responses to scaling

during routine periodontal care. Consistent with previous research, most patients experienced limited pain during scaling $(7,20,22)$ (Fig. 4).

Pain measurement is inherently difficult as it has both physical and psychological aspects (13). It is subjective and dependent on an individual's perceptions. Therefore, a standardized and controlled environment was essential for pain assessment. In our study, one experienced periodontist treated all patients in the same dental chair using the same piezoelectric ultrasonic handpiece and tips in a quiet, distraction-free environment.

The relationship between dental anxiety and socioeconomic status, as measured by education or income level, has not been clearly determined (23). Thus, while conducting our study, we included patients who had passed at least a tenth-grade level of education and belonged in the same socioeconomic group to avoid bias.

Pain is also related to the disease site (24). Patients who presented with supragingival calculus on the mandibular anterior six teeth were included because the density of nerve endings is greater in the anterior region of the mouth than it is in the posterior gingival tissues, and supragingival calculus formation is seen most commonly on the lingual aspects of the mandibular incisors and canines due to the opening of the submandibular salivary gland ducts (3). 
To avoid exaggerated responses, patients were asked to participate in the study only after scaling of the involved teeth had been finished, but before full-mouth scaling. Patients could have become sensitized if they were aware that they were participating in a study. Also, the patients knew that the treatment was not finished at this time, so it was believed that they were not yet relieved of their anxiety or fear.

In the present study, the mean VAS score for the entire study group was $17.3 \pm 13.8$. Karadottir et al. (20) reported the mean VAS score for SRP of two different hygienists as 15.1 and 10.8, and according to Chung et al. (21), these scores were 22.3 and 19.5. Matthews and McCulloch (15) reported a score of 10.6, whereas Canakci and Canakci (13) reported this score as 15.2. In another study of women and men (8), these scores were 17.1 and 15.8, respectively. Guzeldemir et al. (3) reported a mean VAS of 19.91. The mean VAS score obtained in our study was similar to these scores.

The mean VAS scores for women and men were 18.8 \pm 13.6 and $15.7 \pm 14.0$, respectively. Though the pain responses were higher in women than in men, there was no statistically significant gender difference in the mean VAS $(P=0.432)$, which is in agreement with other studies $(8,13,20,25)$.

There were significant differences in dental anxiety scores between the genders. Women reported more dental anxiety than did men, as shown in previous studies $(3,23,26)$. It could be attributed to the fact that men refuse to report symptoms they consider weak or unmasculine and tend to silently cope with anxiety.

The questionnaire used in the present study was developed by Karadottir et al. (20). A significant correlation existed between VAS and each question as well as the total dental anxiety score $(P<0.001)$ except for question numbers 3 and 4 in men.

It was observed that a number of the patients who were anxious prior to the treatment responded to question 4 (If you had to go to the dentist tomorrow, how would you feel about it?) by saying that they would go to the dentist if required or recalled. This response indicates that a positive or neutral experience in the dental office would make the patient more compliant. However, due to the lack of such an option in the questionnaire, the patients chose the next best option. Thus, adding more options to the questionnaire would probably make it more sensitive in detecting the perception of pain.

Often, periodontal therapy is associated with high levels of anxiety. Although a follow-up study by Erten et al. (7) indicated that periodontal therapy was associated with low levels of discomfort, some patients seemed to remain highly anxious throughout the treatment.

Anxiety is thought to influence the effective component of pain (27). Anxious people tend to overestimate the intensity of aversive events such as fear and pain (28). Canakci et al. noted that a patient with a high Corah's DAS score would be more likely to present a high pain response than a patient with a lower DAS score (8). Other studies have also reported that people with higher scores on scales measuring dental anxiety and pain reported more pain after dental treatment $(4,29)$.

A previous unpleasant dental experience is probably the most stated single cause for dental anxiety $(23,30,31)$. However, the 'latent inhibition' theory suggests that a history of positive or neutral dental experiences may serve as a buffer against the development of traumatic associations or experiences (32).

The 'interaction hypothesis' proposes that the impact of constitutional vulnerability (pain sensitivity) on dental distress is dependent on the perception of the situation being dangerous (33). Furthermore, Reiss suggested that patients differed in their fear of pain because of their fear of anxiety, fear of negative evaluation and/or fear of injury (34).

Klages et al. showed that subjects expected more pain than they experienced; this effect was stronger in patients with higher dental-anxiety scores (35). It was also suggested that anxiety has an influence on the expected pain, but not on the experienced pain (36).

van Wijk and Hoogstraten suggested that subjects tended to overestimate their fear of dental pain when they had not experienced the particular pain itself. When the patients were exposed to the feared pain, they would find it less painful than expected, and this could reduce their anxiety levels. They also suggested that the use of anxiolytic agents, anaesthesia, and possibly different anaesthetic procedures may help to reduce the fearful expectations. They supported the assumption that people who are predisposed to responding fearfully to pain are at an increased risk of ending up in a vicious circle of anxiety, fear of pain, and avoidance of dental treatment (28).

This study emphasises the psychodynamic understanding of the dentist-patient interaction, which is a two-person endeavour. It is the dentist working with the patient and the patient being able to accept the treatment provided by the dentist. This interaction requires improved time and behavioural management skills, increased awareness of patients' concerns and anxieties, the ability to readjust treatment plans and to provide patient-centred care (37). Since the attitude toward dentists demonstrates a strong linear relationship with dental anxiety, dentally 
anxious subjects are inclined to develop an unpleasant feeling toward dentists. The genesis of the relationship between dental anxiety and an unfavourable attitude toward dentists is unknown, but it is likely affected by the dentist-patient relationship (23). This could in turn affect the dental treatment plan. Therefore, assessing the patients' level of anxiety using a questionnaire before dental treatment can lead to modification of the treatment plan as needed.

Patients' compliance to dental treatment procedures is found to be affected by many factors, including selfdestructive behaviour, fear, economic factors, health beliefs, stressful events in their lives and perceived indifference of the dentist (16). It has also been found to be influenced in a major way through variables that reduce anxiety and increase satisfaction with the dentist. The most important behaviour associated with anxiety reduction is the dentist's explicit promise to prevent pain. Other dentist behaviour, such as friendliness, being calm, portraying empathy and giving moral support, are closely related to patient satisfaction. Thus, there exists a need for the dentist to be aware of patient anxiety in order to effectively deal with it. This gives the patient permission to express concerns that are present (38).

Higher levels of dental anxiety can lead to the avoidance of dental treatment and can change a patient's perception of pain. In this study, patients experienced only limited pain during scaling. Patients expected pain and thus had anxiety. The fear of pain during treatment has been identified as a major factor in preventing patients from seeking dental care. Therefore, delivering dental care with minimal patient discomfort should be an essential part of a clinician's skills to avoid noncompliance.

Screening of patients' previous dental experiences and histories for more information should be considered so that the dentist may take additional precautions to improve the doctor-patient relationship and thus, the treatment results. With the increasing demand for stress-free and painless therapy, clinicians should have the ability to reduce patients' fear, discomfort and pain during periodontal therapy for successful treatment and sustained maintenance care.

\section{References}

1. Okeson JP (2005) Bell's orofacial pains: the clinical management of orofacial pain. 6th ed, Quintessence, Chicago, 6.

2. Stedman TL (2000) Stedman's medical dictionary. 27th ed, Lippincott Williams \& Wilkins, Baltimore, 1297.

3. Guzeldemir E, Toygar HU, Cilasun U (2008)
Pain perception and anxiety during scaling in periodontally healthy subjects. J Periodontol 79, 2247-2255.

4. Maggirias J, Locker D (2002) Psychological factors and perceptions of pain associated with dental treatment. Community Dent Oral Epidemiol 30, 151-159.

5. Rhudy JL, Meagher MW (2000) Fear and anxiety: divergent effects on human pain thresholds. Pain 84, 65-75.

6. Rizzardo R, Borgherini G, Cappelletti L (1991) Illness behaviour and anxiety in dental patients. $\mathrm{J}$ Psychosom Res 35, 431-435.

7. Fardal O, Hansen BF (2007) Interviewing selfreported highly anxious patients during periodontal treatment. J Periodontol 78, 1037-1042.

8. Canakçi CF, Canakçi V (2007) Pain experienced by patients undergoing different periodontal therapies. J Am Dent Assoc 138, 1563-1573.

9. Chung JE, Koh SA, Kim TI, Seol YJ, Lee YM, Ku Y, Rhyu IC, Chung CP, Koo KT (2011) Effect of eutectic mixture of local anesthetics on pain perception during scaling by ultrasonic or hand instruments: a masked randomized controlled trial. J Periodontol 82, 259-266.

10. Kocher T, Rodemerk B, Fanghänel J, Meissner G (2005) Pain during prophylaxis treatment elicited by two power-driven instruments. J Clin Periodontol 32, 535-538.

11. Portmann K, Radanov BP (1997) Dental anxiety and illness behaviour. Psychother Psychosom 66, 141-144.

12. Langley GB, Sheppeard H (1985) The visual analogue scale: its use in pain measurement. Rheumatol Int 5, 145-148.

13. Canakci V, Canakci CF (2007) Pain levels in patients during periodontal probing and mechanical non-surgical therapy. Clin Oral Investig 11, 377-383.

14. Grant DA, Lie T, Clark SM, Adams DF (1993) Pain and discomfort levels in patients during root surface debridement with sonic metal or plastic inserts. J Periodontol 64, 645-650.

15. Matthews DC, McCulloch CA (1993) Evaluating patient perceptions as short-term outcomes of periodontal treatment: a comparison of surgical and non-surgical therapy. J Periodontol 64, 990-997.

16. Braun A, Jepsen S, Krause F (2007) Subjective intensity of pain during ultrasonic supragingival calculus removal. J Clin Periodontol 34, 668-672.

17. Corah NL (1969) Development of a dental anxiety 
scale. J Dent Res 48, 596.

18. Dailey YM, Humphris GM, Lennon MA (2001) The use of dental anxiety questionnaires: a survey of a group of UK dental practitioners. Br Dent J 190, 450-453.

19. Kleinknecht RA, Klepac RK, Alexander LD (1973) Origins and characteristics of fear of dentistry. J Am Dent Assoc 86, 842-848.

20. Karadottir H, Lenoir L, Barbierato B, Bogle M, Riggs M, Sigurdsson T, Crigger M, Egelberg J (2002) Pain experienced by patients during periodontal maintenance treatment. J Periodontol 73, 536-542.

21. Chung DT, Bogle G, Bernardini M, Stephens D, Riggs ML, Egelberg JH (2003) Pain experienced by patients during periodontal maintenance. $\mathrm{J}$ Periodontol 74, 1293-1301.

22. Sullivan MJ, Neish NR (1998) Catastrophizing, anxiety and pain during dental hygiene treatment. Community Dent Oral Epidemiol 26, 344-349.

23. Doerr PA, Lang WP, Nyquist LV, Ronis DL (1998) Factors associated with dental anxiety. J Am Dent Assoc 129, 1111-1119.

24. Heins PJ, Karpinia KA, Maruniak JW, Moorhead JE, Gibbs CH (1998) Pain threshold values during periodontal probing: assessment of maxillary incisor and molar sites. J Periodontol 69, 812-818.

25. Pihlstrom BL, Hargreaves KM, Bouwsma OJ, Myers WR, Goodale MB, Doyle MJ (1999) Pain after periodontal scaling and root planing. J Am Dent Assoc 130, 801-807.

26. Erten H, Akarslan ZZ, Bodrumlu E (2006) Dental fear and anxiety levels of patients attending a dental clinic. Quintessence Int 37, 304-310.

27. Woolgrove J (1983) Pain perception and patient management. Br Dent J 154, 243-246.

28. van Wijk AJ, Hoogstraten J (2005) Experience with dental pain and fear of dental pain. J Dent Res 84, 947-950.

29. Sullivan MJ, Neish NR (1997) Psychological predictors of pain during dental hygiene treatment. Probe 31, 123-126.

30. Locker D, Shapiro D, Liddell A (1996) Negative dental experiences and their relationship to dental anxiety. Community Dent Health 13, 86-92.

31. Poulton R, Thomson WM, Davies S, Kruger E, Brown RH, Silva P (1997) Good teeth, bad teeth and fear of the dentist. Behav Res Ther 35, 327-334.

32. Davey GC (1989) Dental phobias and anxieties: evidence for conditioning processes in the acquisition and modulation of a learned fear. Behav Res Ther 27, 51-58.

33. King PR, Endlerb NS (1992) Interactional anxiety and dental treatment: an empirical test of a composite predictor for state anxiety. Pers Individ Differ 13, 85-89.

34. Reiss S (1987) Theoretical perspectives on the fear of anxiety. Clin Psychol Rev 7, 585-596.

35. Klages U, Ulusoy O, Kianifard S, Wehrbein $\mathrm{H}$ (2004) Dental trait anxiety and pain sensitivity as predictors of expected and experienced pain in stressful dental procedures. Eur J Oral Sci 112, 477-483.

36. Rachman S, Arntz A (1991) The overprediction and underprediction of pain. Clin Psychol Rev 11, 339-355.

37. Freeman R (1999) Apsychodynamic understanding of the dentist-patient interaction. Br Dent J 186, 503-506.

38. Corah NL (1988) Dental anxiety. Assessment, reduction and increasing patient satisfaction. Dent Clin North Am 32, 779-790. 